\title{
BMJ Open Monitoring the use of lipid-lowering medication among persons with newly diagnosed diabetes: a nationwide register-based study
}

\author{
Tuulikki Vehko, ${ }^{1}$ Reijo Sund, ${ }^{1}$ Martti Arffman, ${ }^{1}$ Kristiina Manderbacka, ${ }^{1}$ \\ Pirjo llanne-Parikka, ${ }^{2}$ Ilmo Keskimäki ${ }^{1,3}$
}

To cite: Vehko T, Sund R, Arffman M, et al. Monitoring the use of lipid-lowering medication among persons with newly diagnosed diabetes: a nationwide register-based study. BMJ Open 2013;3:e003414. doi:10.1136/bmjopen-2013003414

- Prepublication history for this paper is available online. To view these files please visit the journal online (http://dx.doi.org/10.1136/ bmjopen-2013-003414).

Received 14 June 2013 Revised 30 August 2013 Accepted 25 September 2013

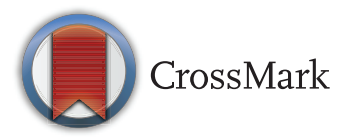

${ }^{1}$ Service System Research Unit, National Institute for Health and Welfare (THL), Helsinki, Finland

${ }^{2}$ The Finnish Diabetes

Association, Tampere, Finland

${ }^{3}$ Health and Social Policy, School of Health Sciences, University of Tampere, Tampere, Finland

Correspondence to Tuulikki Vehko; tuulikki.vehko@thl.fi

\section{ABSTRACT}

Objectives: To develop a register-based monitoring system to provide information on the use of lipid-lowering medication among persons with diabetes in different patient groups and by socioeconomic position.

Design: Longitudinal and register-based, before and after diabetes diagnosis.

Setting: Finnish population.

Participants: A total of 121053 persons aged 30-79 years with a new diagnosis of diabetes during 2000-2006. The annual cohorts were divided at the time of diabetes diagnosis by coronary heart disease (CHD) status.

Primary and secondary outcome measures: Lipid-lowering medication purchases after diabetes diagnosis and prior to the diagnosis.

Results: According to the health insurance reimbursement data the use of lipid-lowering medication advanced rapidly among people with diabetes in the early 2000s in Finland. Of the patients diagnosed with diabetes in 2000 only one-fourth used lipid-lowering medication in 6-12 months after their diagnosis. For those diagnosed in 2006, the utilization rate was $46 \%$. Among those with a history of $\mathrm{CHD}$ the use of medication was markedly higher; $51-58 \%$ in 2000 and $77-79 \%$ in 2006. Taking into account the increasing trend and measuring the independent effect of the diagnosis of diabetes on lipid-lowering medication, setting the diagnosis increased the use by $10-50 \%$. Despite increasing overall utilisation rates, socioeconomic difference in the use of lipid-lowering medication remained throughout the study period. In particular, the lowest income quintile differed from other income groups and in 2006 its use of lipid-lowering medication remained approximately $10 \%$ points lower compared with the overall level.

Conclusions: The lipid-lowering medication is being applied in an increasing population of new diabetes cases; however, modelling the independent effect of the diagnosis of diabetes on lipid-lowering medication shows that the diagnosis increased use, but did not abolish socioeconomic differences.

\section{Strengths and limitations of this study}

- We examined individual-level data from several registers, including prescriptions and all public and private hospitals in Finland. The longitudinal data enabled us to stratify a real-life population of newly diagnosed diabetes patients according to onset of coronary heart disease, and adjust for several comorbidities in the analysis.

- Register-based data do not have information about behavioural components of CHD management.

- Register-based data do not enable us to determine which of the differences in the use of lipid-lowering medication are due to nonprescription by doctors and which to nonadherence by patients.

\section{INTRODUCTION}

Use of lipid-lowering medication has increased in the general population in Western countries since the $1990 \mathrm{~s} .{ }^{1}$ In the year 2000 , the level of statin consumption in Finland was around the European average. ${ }^{2}$ Earlier studies from Finland have reported that statin use has increased from the middle of the 1990s to the early 2000s in the general population, among the elderly, and in persons with acute coronary infarction and in those with newly diagnosed coronary heart disease (CHD) ${ }^{3-5}$ However, some studies have suggested that the use of lipid-lowering medication has been lower among CHD patients diagnosed with diabetes than among those without diabetes. ${ }^{45}$

Cardiovascular risk reduction among patients with high risk is a multifaceted regimen that includes evidence-based use of medications. International and national guidelines recommend that for persons with diabetes and at high risk of cardiovascular diseases, and where the goals for lipid levels 
have not been met by lifestyle changes, physicians should prescribe lipid-lowering medication as a part of a tailored treatment programme. ${ }^{6-10}$ Clinical guidelines indicate that diabetes should be considered as a major risk factor for cardiac complications. For this reason, a national 10-year Development Programme for the Prevention and Care of Diabetes (DEHKO) was launched in Finland in 2000. The programme focussed on preventing type 2 diabetes, improving early diagnosis of type 2 diabetes and preventing diabetes-related complications. ${ }^{11} \mathrm{~A}$ health insurance reform in 2000 provided a higher reimbursement for lipid-lowering medication costs for CHD patients. ${ }^{12}$ Later (2003), generic substitution was introduced in Finland. This procedure provided an opportunity that the dispensing pharmacy substitute a prescribed preparation with the cheapest interchangeable product. ${ }^{13}$ Simultaneously with these changes, the consumer prices of lipid-lowering medication decreased.

Studies on the consistency of guidelines and the trends of lipid-lowering medication among persons with diabetes with or without CHD have been reported in the Nordic countries, ${ }^{14-16}$ and also in other Western countries. ${ }^{17-27}$ Statin use was found to be less common among those with diabetes alone compared with those with diabetes and CHD, raising concerns about undertreatment. Earlier studies have further described gender and age differences in the use of these drugs. Socioeconomic differences in the use of statin treatment have been examined in some studies, for example, a study in Norway reported that among patients with a history of cardiovascular disease or diabetes, the medication was more common in patients with the highest education, especially for women. ${ }^{16}$ A regional study from the UK reported that prescribing of statins to patients with diabetes was higher among patients with a South Asian origin compared with those with a Caucasian or African origin. ${ }^{22}$ A study from Denmark reported that both ethnic background and income were associated with disparities in statin treatment in persons with diabetes. ${ }^{28}{ }^{29}$ Similar results of lower statin use among diabetes patients with low income have been reported in the USA. ${ }^{30}$ Most studies have examined lipid-lowering medication use among the prevalent diabetic population and less is known about the use of lipid-lowering medication among the newly diagnosed (incident) diabetic population.

\section{Aim of the study}

This nationwide longitudinal study monitors the trends of lipid-lowering medication and factors related to medication use in individual-level data obtained from linkages between health insurance and care registers covering the whole population. We investigate how the use of lipid-lowering medication has changed during the period 2000-2006, using annual cohorts of newly diagnosed diabetes patients by sex, age and income as an indicator of socioeconomic position. Since CHD is a main indication for lipid-lowering medication use, we expect that the medication use is more common among persons with a history of CHD already before the diabetes diagnosis. Likewise, we expect that the impact on medication use may differ among those with simultaneous diabetes and CHD diagnoses and those diagnosed for diabetes alone. We therefore analyse three groups of persons with newly diagnosed diabetes: those with a diabetes diagnosis only, those with coincident diabetes and CHD diagnoses, and those with a CHD diagnosis before the diabetes diagnosis. Additionally, we describe changes in each annual cohort in the lipid-lowering medication use at the time of diabetes diagnosis by comparing the level of use after the diagnosis to that before it.

\section{METHODS}

Setting

The Finnish healthcare system operates on universal coverage, and is mainly funded by tax revenues, with small out-of-pocket payments being made by patients in both inpatient and outpatient care for public health services (up to a maximum sum of $€ 590$ in 2006). There were three reimbursement categories for the costs of prescribed medicines: basic ( $42 \%$ of the price), lower special $(72 \%)$ and higher special (100\%, excluding a $€ 3$ copayment for each medicine purchased at one time). To obtain a special reimbursement for a diagnosed chronic disease a certificate from a physician must be approved at the Social Insurance Institution which administrates the reimbursements in Finland. CHD-specific medication qualifies in the lower special reimbursement category and diabetes-specific medication in the higher special reimbursement category. ${ }^{12}$ In addition, there was an annual copayment ceiling for prescribed medicines ( $€ 617$ in 2006), with the cost of all prescribed medicines beyond that limit being reimbursed $(100 \%$, excluding a $€ 1.5$ copayment for each purchase). Lipid-lowering medication costs are reimbursed for persons with diabetes according to the basic reimbursement and for persons with CHD according to the lower special reimbursement scheme. ${ }^{31}$

\section{Study data}

The nationwide diabetes population was identified from several national Finnish health insurance and healthcare registers, including the Hospital Discharge Register, the Cause of Death Statistics, the Register on Medical Special Reimbursements and the Register on Reimbursed Drug Purchases. The annual cohorts for the years 2000-2006 included 121053 persons who were aged 30-79 years and diagnosed with diabetes within a calendar-year, had no prior history of diabetes in registers, were not institutionalised on a long-term basis and had survived at least 1 year after the diabetes diagnosis (67 357 men and 53696 women). In these annual cohorts, diabetes was defined using ICD-10 (E10-14); entitlements to elevated reimbursement for antidiabetic medications (Finnish Code 103) and entry of purchase of antidiabetic medications (Anatomical Therapeutic Chemical (ATC) codes A10). 
The technical compilation of the prevalent diabetic population is described in detail elsewhere. ${ }^{32}$ For variables regarding medication use and comorbidities for these annual cohorts, the study data included information from 1998 to 2007 (figure 1).

\section{Variables}

Income was used as a measure for a socioeconomic position in the current study since it is likely to capture the individual's socioeconomic position at the time of the diagnosis better than, for example, education or occupational social class, which are less subject to change after young adulthood. Data on income were extracted from the individual-level annual employment statistics compiled by Statistics Finland. Income was classified into quintiles according to family disposable income, with an adjustment for family size according to the OECD equivalence scale.

CHD status was extracted from the register of patients eligible for special reimbursement for expenditure due to CHD medicines (Finnish code 206), and from the Hospital Discharge Register for hospital inpatient treatment due to CHD (International Classification of Diseases (ICD)-9 410-414; ICD-10: I20-I25). Based on information from several registers, persons were categorised to non-insulin-treated diabetes mellitus (NITDM), and insulin-treated diabetes mellitus (ITDM) groups. ${ }^{32}$ Comorbidities (appendix 1) come from the period before the diabetes diagnosis and they were identified in these registers using a method developed for Finnish data. ${ }^{33}$

Lipid-lowering medication purchases were obtained from the Register on Reimbursed Drug Purchases, which is coded using the ATC system (C10 for lipid-lowering medication). ${ }^{34}$ At the national level in these study years the most common of this therapeutic group medications were statins ${ }^{12} 31$; the proportion were $96 \%$ in 2006.

As we were interested in lipid-lowering medicine use in the proximity of diabetes diagnosis, we had to define suitable observation windows to detect medication use before and after the diagnosis from the register-based data on drug purchases. One prescription may include drugs for a 3-month period, so we considered that a 6-month observation window is suitable to detect all persons on medication. We used two observation windows in this study: (1) purchases 24-30 months before diabetes diagnosis, which we considered to reflect the medication status clearly before the diabetes diagnosis and (2) purchases 6-12 months after diabetes diagnosis, which we considered to reflect a stabilised situation after the diagnosis of diabetes (figure 1). These definitions were supported by our preliminary analyses using cumulative and smoothed hazard functions to investigate the duration to the first purchase before and after the diabetes diagnosis. The use of these definitions required us to exclude persons who had died within a year of a diabetes diagnosis from the study cohorts.

As CHD is the main indicator of lipid-lowering use and we have longitudinal data, we stratified persons with a new diabetes diagnosis according to their CHD status: persons with diabetes and no information on CHD before or during the first year after diabetes diagnosis as recorded in the data; persons with CHD at least 1 year before diabetes diagnosis and persons with a diagnosis of CHD in the year before or after the diabetes diagnosis, that is, coincident diagnosis of CHD and diabetes. We used a \pm 1 -year window around the date of first recorded diabetes diagnosis to compensate for possible uncertainties or delays in the simultaneous diagnoses of CHD and diabetes.

\section{Statistical analysis}

To describe the trend of the lipid-lowering medication use we calculated proportions (\%) of persons with at least one purchase in the observation window for each annual cohort of new diabetes cases stratified by income quintile. As CHD is the main indication for lipid-lowering medication use, we examined changes in lipid-lowering medication use by stratifying the study population according to
Figure 1 Construction of patient groups and observation windows for lipid-lowering medication purchases in relation to the time.

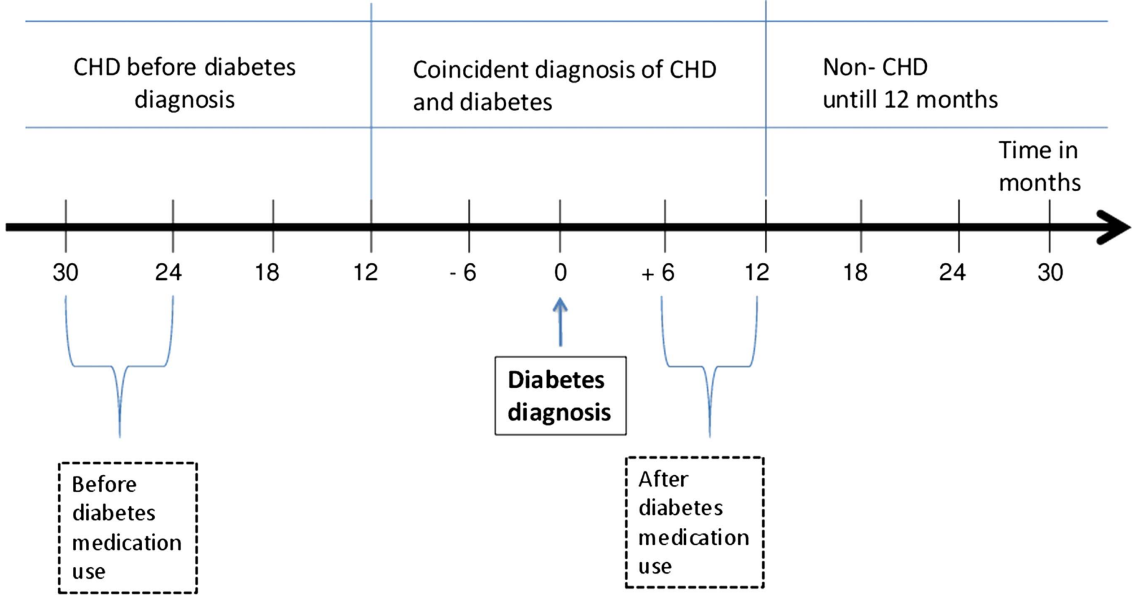


CHD status. In addition to the calculation of unadjusted proportions, we also calculated the risk-adjusted proportions of medication users for each stratum so that the groups could be compared without bias effects originating from the between-group differences in the distributions of uninteresting (confounding) variables. Risk-adjustment was performed using a technique in which the ratio between the observed numbers of medication users $(\mathrm{O})$ and the expected numbers (E) of users in the groups of interest was calculated first and then scaled back to proportions by multiplying the obtained $\mathrm{O} / \mathrm{E}$-ratios by the observed mean proportion of medication users during the entire observation period. As the adjusted proportions were scaled using the $\mathrm{O} / \mathrm{E}$ ratios, CIs were calculated using a Poisson assumption for observed counts. ${ }^{33}$ The estimated numbers of cases were derived for each group by aggregating individual-level predictions obtained from logistic regression analysis in which individual-level medication use was the dependent variable and age, sex as well as several comorbidities (alcohol-related problems; atherosclerosis; cancer; chronic obstructive pulmonary disease (COPD) and asthma; dementia; depression; epilepsy; Parkinson's disease; mental disorders and stroke) were independent variables. ${ }^{35}$ As the increase in the general trend of lipid-lowering medication use was rapid during the study period, it was expected that the mean change in the proportions for medication users from the time preceding the diabetes diagnosis to the time following the diabetes diagnosis would be higher than the standard risk-adjustment model would predict. Therefore, we further adjusted the proportions presented in figure 3 for the expected increase in medication use so that the proportions of before and after diabetes diagnosis could be directly compared. In other words, we wanted to remove the effect of an observed population-level trend in increasing proportions of medications users from the pre-post comparisons so that the independent effect of diabetes diagnosis could be observed. This further adjustment was made by first fitting linear regression models for the annual proportions to obtain an estimate of slope for a trend and then adjusting prediabetes proportions and corresponding CIs so that the expected non-diabetes-specific calendar-time-related change from prediabetes measurement to postdiabetes measurement period ( 3 years) could be eliminated. The final adjusted proportions should be interpreted as proportions that are comparable to assessing the effect of diabetes diagnosis on medication use in different groups of interest.

\section{Ethics}

In accordance with data protection legislation in Finland, the register linkages were undertaken by competent statistical authorities and the research group received anonymised data. The study protocol was approved by the Research Ethics Committee of the National Institute for Health and Welfare. Permissions to use data were sought from the National Institute for Health and Welfare for hospital inpatient care, the Social Insurance Institution for special reimbursement rights for medicine costs and for lipid-lowering medicine purchases and from Statistics Finland for sociodemographic variables and cause of death statistics. The data protection measures were agreed with Statistics Finland as the proper statistical authority and the data linkages were considered to be appropriate by the office of the Finnish data protection ombudsman.

\section{RESULTS}

The register-based data showed a considerable increase in the use of lipid-lowering medication among persons with newly diagnosed diabetes (figure 2). The increase took place in each annual cohort and in all income quintiles, but the proportion of users in the lowest income group remained lower than that in the highest group. The number of persons with newly diagnosed diabetes increased 34\% during 2000-2006 (table 1). Of the study population, $18 \%$ were younger than 50 years and one-fourth were aged 70-79 years. The population comprised mainly of persons with NITDM, and only $4 \%$
Figure 2 Unadjusted proportion of persons with newly diagnosis diabetes using lipid-lowering medication by income quintiles in 2000-2006 in Finland.

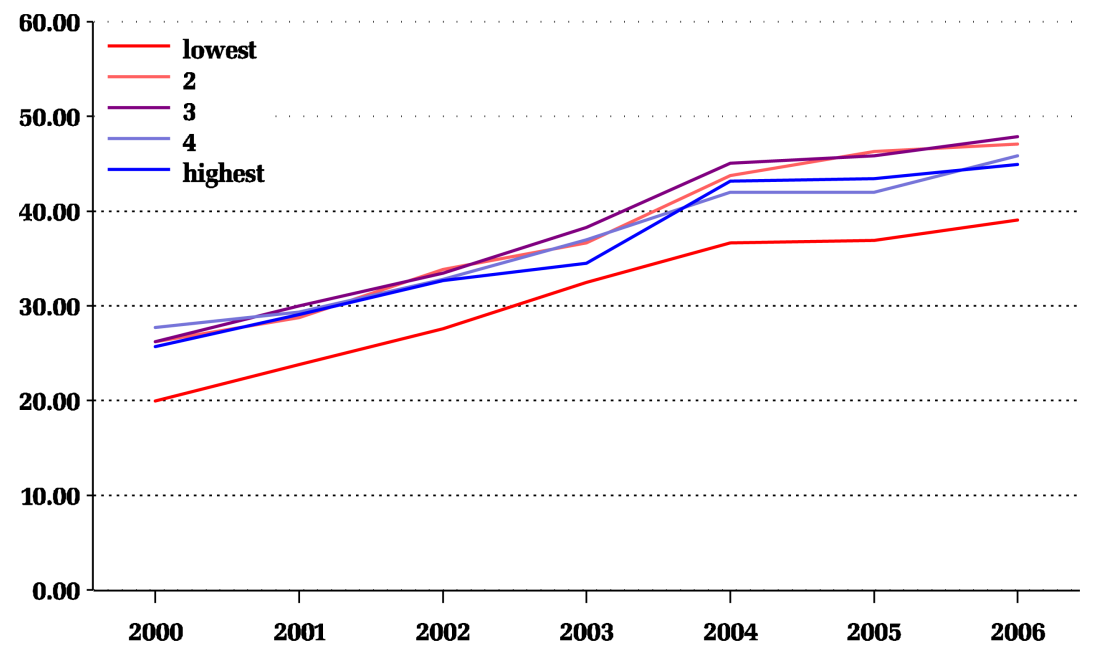


Figure 3 Adjusted proportions of persons on the lipid-lowering medication before and after diabetes diagnosis by income fifth, annual cohorts 2000-2006. Adjusted for age, sex, comorbidities and temporal trend.

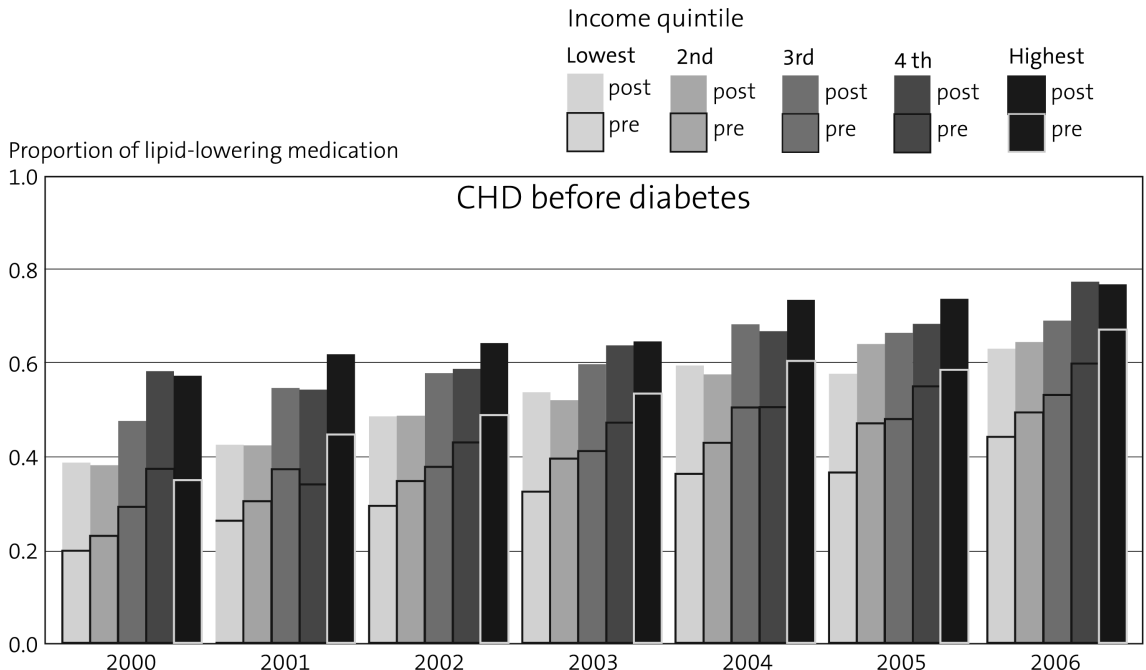

Proportion of lipid-lowering medication

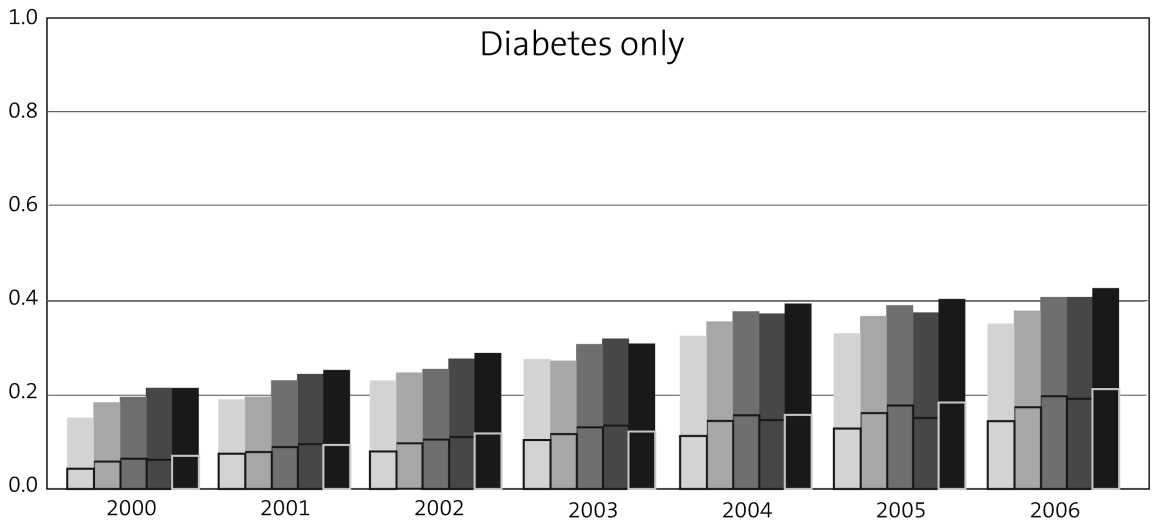

Proportion of lipid-lowering medication

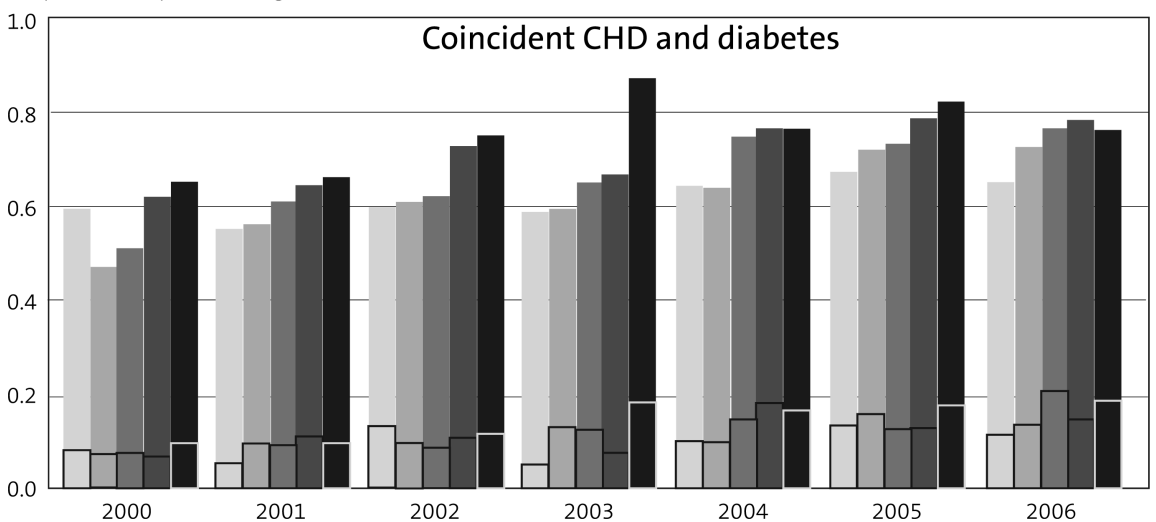

had ITDM. From 2000 to 2006, there was an increase in the non-CHD-related COPD and asthma as well as depression. The relative contraindications (eg, cancer, dementia and alcohol-related problems) for lipid-lowering medication use were rare. In line with earlier studies concerning persons with diabetes, depression was relatively common, and $7 \%$ had other mental problems. Those diagnosed with diabetes alone were the largest group (varying between 11776 and 16290 for the annual cohorts of incident diabetes), those with CHD prior to a diabetes diagnosis totalled approximately 2000 for each study year (range 19432678) and the numbers of those with coincident diagnoses varied from 731 to 842 . In terms of age distribution, those with diabetes alone were youngest and those with CHD before diabetes were among the oldest.

Use of lipid-lowering medication increased in all patient groups throughout the annual cohorts (table 2). The level of medication use was low among persons with diabetes-only in 2000 compared with persons with CHD before or coincident with diabetes. In absolute terms, the unadjusted proportions after diabetes diagnosis 
Table 1 Characteristics of all annual cohorts and at the start (2000) and the end (2006) of the study period

\begin{tabular}{|c|c|c|c|c|}
\hline Characteristics & $\mathbf{N}$ & $\begin{array}{l}\text { All annual cohorts } \\
\mathrm{N}=121053 \\
\text { Per cent }\end{array}$ & $\begin{array}{l}\text { The cohort } 2000 \\
\mathrm{~N}=14516 \\
\text { Per cent }\end{array}$ & $\begin{array}{l}\text { The cohort } 2006 \\
\mathrm{~N}=19462 \\
\text { Per cent }\end{array}$ \\
\hline Men & 67357 & 56 & 54 & 57 \\
\hline Women & 53696 & 44 & 46 & 43 \\
\hline \multicolumn{5}{|l|}{ Age group } \\
\hline $30-39$ & 5527 & 5 & 5 & 5 \\
\hline $40-49$ & 15660 & 13 & 13 & 13 \\
\hline $50-59$ & 36868 & 30 & 29 & 30 \\
\hline $60-69$ & 34177 & 28 & 28 & 29 \\
\hline 70-79 & 28821 & 24 & 25 & 23 \\
\hline \multicolumn{5}{|l|}{ Income quintile } \\
\hline Lowest & 19720 & 16 & 17 & 17 \\
\hline 2nd & 29794 & 25 & 26 & 23 \\
\hline 3rd & 24391 & 20 & 20 & 20 \\
\hline 4th & 22689 & 19 & 18 & 19 \\
\hline Highest & 24459 & 20 & 20 & 21 \\
\hline \multicolumn{5}{|c|}{ Patients may have several comorbidities } \\
\hline Alcohol-related problems & 569 & 0.5 & 0.5 & 0.4 \\
\hline Atherosclerosis & 411 & 0.3 & 0.5 & 0.3 \\
\hline Cancer & 3298 & 2.7 & 2.2 & 3.2 \\
\hline COPD and asthma & 15685 & 13.0 & 12.0 & 13.7 \\
\hline Dementia & 619 & 0.5 & 0.3 & 0.6 \\
\hline Depression & 13885 & 11.5 & 10.8 & 12.6 \\
\hline Epilepsy & 3946 & 3.3 & 2.6 & 4.4 \\
\hline Parkinson's disease & 887 & 0.7 & 0.6 & 0.9 \\
\hline Mental disorders & 7975 & 6.6 & 6.6 & 6.7 \\
\hline Stroke & 1300 & 1.1 & 1.2 & 1.1 \\
\hline
\end{tabular}

increased during 2000-2006 by $20 \%$ points among persons with diabetes alone and with coincident CHD and diabetes, and by $26 \%$ points among persons with CHD before diabetes. The diagnosis of CHD was the main determinant of lipid-lowering medication use but the use of lipid-lowering medication in the diabetes-only group in the most recent cohort were almost at the same level as those with CHD before diabetes in 2000 . The differences between the unadjusted and adjusted proportions among persons with CHD before or coincident with a diabetes diagnosis indicate that part of the lipid-lowering medication use was attributable to differences in distributions of age, sex and comorbidity between the groups and therefore we present the results according to these groups (table 3 ).

The lipid-lowering medication use after the diabetes diagnosis was similar among men and women by history of CHD (table 3). Comparing the study years 2000 and 2006, lipid-lowering medication use increased to a new level in all age groups among persons with diabetes-only and among persons with CHD before diabetes. In all patient groups the oldest age group (70-79 years old) used less lipid-lowering medication compared with 5059 years old. Among persons with diabetes-only, the youngest age group used less medication than the 50-year-olds to 69-year-olds. We found statistically

Table 2 Use of lipid-lowering medication by CHD status among people with newly diagnosed diabetes, unadjusted and adjusted proportions (\%) and their $95 \% \mathrm{Cl}$, for the cohorts 2000 and 2006

\begin{tabular}{|c|c|c|c|c|c|c|c|c|}
\hline \multirow[b]{3}{*}{ CHD status } & \multicolumn{4}{|c|}{ The cohort 2000} & \multicolumn{4}{|c|}{ The cohort 2006} \\
\hline & \multicolumn{2}{|c|}{ Unadjusted } & \multicolumn{2}{|c|}{ Adjusted* $^{*}$} & \multicolumn{2}{|c|}{ Unadjusted } & \multicolumn{2}{|c|}{ Adjusted* $^{\star}$} \\
\hline & $\%$ & $95 \% \mathrm{Cl}$ & $\%$ & $95 \% \mathrm{Cl}$ & $\%$ & $95 \% \mathrm{Cl}$ & $\%$ & $95 \% \mathrm{Cl}$ \\
\hline Diabetes-only & 19 & (18 to 20$)$ & 19 & (19 to 20$)$ & 39 & (38 to 40$)$ & 40 & (39 to 41$)$ \\
\hline $\mathrm{CHD}$ before diabetes & 51 & (48 to 53 ) & 47 & (44 to 50$)$ & 77 & (75 to 79 ) & 70 & (67 to 73 ) \\
\hline Coincident CHD and diabetes & 58 & (55 to 62 ) & 55 & (50 to 60$)$ & 79 & (76 to 82 ) & 73 & (68 to 80$)$ \\
\hline
\end{tabular}




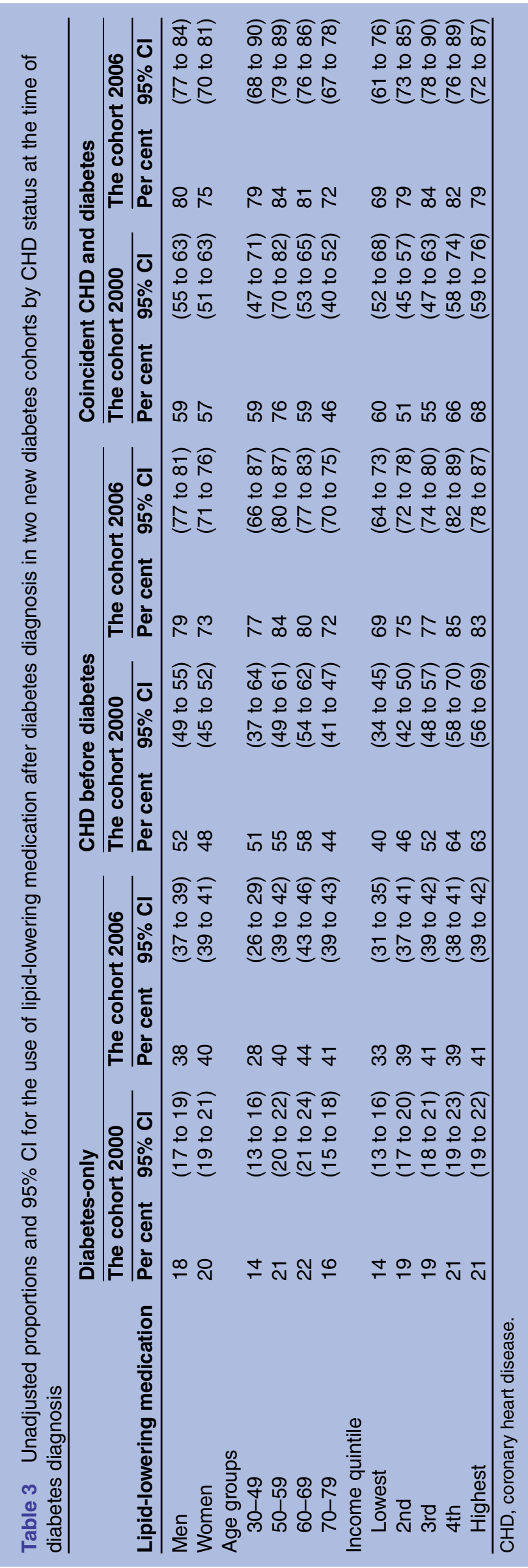

significance differences in comorbidity-specific proportions within persons with diabetes-only; the use was lower in those with alcohol-related problems: $8 \%(95 \%$ CI $1 \%$ to $14 \%$ ) in 2000 , and $14 \%$ (95\% CI $6 \%$ to $22 \%$ ) in 2006. Among patients with diabetes-only the medication use was lower in the lowest income group compared with higher income groups, among patients with CHD before diabetes, an income-related gradient in lipid-lowering medication use was detected; but among persons with coincident CHD and diabetes the differences between income groups were not systematic.

To estimate the impact of receiving a diabetes diagnosis on the uptake of lipid-lowering medication in these seven annual cohorts of persons with newly diagnosed diabetes we compared medication use prior to diabetes diagnosis and after the diagnosis, taking their CHD status into account. Owing to an increasing overall trend of lipid-lowering medication use and the time frame of 30 months or more between measurements points (see figure 1), the proportions were also adjusted for temporal trends to see whether the independent part of the change was related to the diagnosis of diabetes.

After the diabetes diagnosis, the use of lipid-lowering medication was clearly lower among persons with diabetes-only compared with persons with CHD before or coincidental with diabetes throughout the study period (figure 3, the posterior bars). The use was similar in both groups with CHD. There was a socioeconomic pattern in all patient groups: those in the higher income groups more often received lipid-lowering medication. Based on 95\% CIs (appendix 2) between income groups, differences in medication use were systematic throughout the study years among persons with diabetes-only and among persons with CHD prior to a diabetes diagnosis until 2001.

Comparisons of lipid-lowering medication use before and after the diabetes diagnosis showed an increase throughout the study period in all patient groups and all socioeconomic groups. While the overall medication use increased, changes after a diabetes diagnosis were similar in all annual cohorts. The largest increase (about $50 \%$ points) in lipid-lowering medication use was after a diabetes diagnosis among persons with coincident CHD and diabetes, while the increase was about $20 \%$ points among both persons with diabetes-only and persons with CHD before diabetes.

\section{DISCUSSION}

The overall use of lipid-lowering medication increased rapidly in all annual cohorts of persons with newly diagnosed diabetes, which is in line with previous results concerning the prevalent diabetes population. ${ }^{36}$ The use increased in all socioeconomic groups, but despite the increase the use remained lower in the lowest income group compared with the highest group. Persons with newly diagnosed diabetes proved not to be a homogenous group in terms of medication use, but were rather 
separate groups based on the presence of CHD and timing of its onset. Lipid-lowering medication use was lower throughout the study period among persons receiving a diabetes diagnosis without CHD. In the cohort with a diabetes diagnosis in 2006, the proportion was almost $40 \%$ among persons with diabetes-only, while the numbers were almost twice as high among persons with prior or coincident CHD.

As expected, the use of lipid-lowering medication before diabetes diagnosis was modest among persons without prior or coincidental CHD while belonging to a high-risk group. In a meta-analysis, lipid-lowering medication is recommended for patients with diabetes, ${ }^{37}$ but in another meta-analysis a small increase in diabetes risk (RR 1.13 (95\% CI 1.03 to 1.23)) was associated with the use of statins. ${ }^{38}$ However, our study was not designed to address the possible effect of statin use on the risk of diabetes, but instead, to describe the use of lipid-lowering medication before and after diabetes diagnosis.

Our results showed that a diagnosis of diabetes increased lipid-lowering medication use in all patient groups. The increase in the use of lipid-lowering medication was highest among patients with coincidental CHD and diabetes. An obvious reason behind variations between those with coincident diabetes and CHD and those with diabetes-only may be that the risk of poorer vascular outcomes is higher in the group with CHD and therefore the need for medication might be perceived as greater. Nevertheless, the reasons for differences between-patient groups need to be further clarified.

In the group with diabetes-only and in the group with CHD before diabetes the use of lipid-lowering medication was more common among the highest income quintile compared with the lowest income quintile. In the smallest patient group with coincident CHD and diabetes, no socioeconomic differences were found at the end of the monitoring. At that time, the Finnish National Health Insurance reimburses the costs for lipid-lowering medication for those diagnosed for CHD according to the lower special reimbursement scheme, whereas the diagnosis of diabetes entitles one for basic reimbursement only.

A study from the USA has reported that after an increase in the patient's copayment for lipid-lowering medication the use decreased. ${ }^{39}$ Although the costs of lipid-lowering medication in Finland dropped considerably during the years studied, it is still possible that the different levels of reimbursement may be a factor in the lower level of medication use among lower socioeconomic position in the diabetes-only group. Healthcare based on universal coverage could be expected to provide services that narrow the gap between the socioeconomic groups in evidence-based treatment. However, according to our findings, socioeconomic differences in the use of lipid-lowering drugs seem to exist after diabetes diagnosis. During the study period, use of lipid-lowering drugs was increasing. Earlier research concerning the diffusion of healthcare technology (including drugs) suggests that the more common the technology is, the less inequity is involved. ${ }^{40}$ It should be borne in mind that our study was completed in 2006 and since then high-income groups with CHD may have reached a ceiling in the use of lipid-lowering drugs. Further studies are needed to show whether these socioeconomic patterns will dilute in the future.

The research literature available does not define what would be the appropriate levels of medicine use for persons with diabetes. The use of lipid-lowering medication varies in studies from other countries. In Sweden, $25 \%$ of persons with diabetes were treated with statins in $2004,{ }^{14}$ in Germany, the numbers treated with statins were similar, while dividing statin users by history of CHD, stroke or peripheral arterial occlusive disease, the proportion was $38 \%$, while without atherosclerotic complications, it was $19 \%$ in $2003 .{ }^{20}$ Another study (2002) from Germany reported that among persons with diabetes and hypertension, $83 \%$ were treated with statins, and among persons with diabetes and dyslipidaemia the proportion was 29\%. ${ }^{19}$ A study from Denmark reported that $51 \%$ of diabetes patients use statins in $2006 .{ }^{29} \mathrm{~A}$ study from one region in the UK reported that prescription of statins to patients with diabetes varied from $22 \%$ to $31 \%$ in $2002 .^{22}$ In Ireland, $40 \%$ of diabetic patients were treated with statins in $2002^{18}$; and in the USA, $25 \%$ of diabetes patients in $2004 .^{26}$ An Australian study examined persons with diabetes and evaluated $23 \%$ of them to be in need of medication in 2002. ${ }^{27}$ Longitudinal studies from other countries have reported an upward trend in the use of lipid-lowering medication among persons with diabetes. A straightforward comparison between the studies is difficult since the inclusion criteria for onset of diabetes and CHD-related comorbidities vary. Information on nationwide trends in the treatment practices of lipid-lowering medication in incident diabetes is scarce.

The use of a population-based cohort design that incorporated unselected individual-level data allowed us to analyse the use of lipid-lowering medication in a real population with newly diagnosed diabetes. Studies looking at the use of lipid-lowering medication that also take into account the onset of CHD are scarce. A further strength of our data is the ability to adjust for several comorbidities in the analysis. Individual-level information on socioeconomic position helped to prevent ecological bias, while the use of nationwide register data guaranteed a better representation of persons from all socioeconomic groups, especially compared with samples typically drawn for randomised clinical trials. ${ }^{41}$

The diagnosis groups were identified from administrative registers; in Finland these registers do not provide clinical information. The special reimbursement for medicine costs requires a physician's certificate that confirms that certain diagnostic criteria have been met, and a second specialist review of these certificates ensures that false-positive cases in the register are likely to be rare. The determination for use of lipid-lowering medication was based on actual purchases of prescription drugs. Our data do not enable us to determine which of the differences in the use of lipid-lowering medication 
are due to non-prescription by doctors and which to non-adherence by patients. During the study period, prices for lipid-lowering medication were continuously decreasing and, moreover, following generic substitution (introduced in April 2003), all patients could choose a cheaper generic alternative in a pharmacy. ${ }^{42}$ However, our study of monitoring treatment trends provides only indirect evidence on the potential effect of reimbursement schemes or prescription practices on drug use.

\section{CONCLUSIONS}

The results of this monitoring study indicate that lipid-lowering medication use increased in persons with newly diagnosed diabetes, which complemented findings from the general population, but also raise concerns about persistent socioeconomic differences in medication use. Our findings suggest that more attention should be paid to the diabetes population to guarantee effective risk management of cardiac complications.

Contributors TV designed the study, interpreted the data and drafted the article. RS was involved in acquisition of the data, designed the study conducted data analysis, and revised the article. MA carried out data analysis and revised the article. KM and IK designed the study, interpreted the data and revised the article; PI-P interpreted the data and revised the article.

Funding The study was financially supported by the Social Insurance Institution but the institution had no involvement in the study design, data collection, findings or decision to publish.

Competing interests None.

Ethics approval Institutional ethics committee.

Provenance and peer review Not commissioned; externally peer reviewed.

Data sharing statement No additional data are available.

Open Access This is an Open Access article distributed in accordance with the Creative Commons Attribution Non Commercial (CC BY-NC 3.0) license, which permits others to distribute, remix, adapt, build upon this work non-commercially, and license their derivative works on different terms, provided the original work is properly cited and the use is non-commercial. See: http://creativecommons.org/licenses/by-nc/3.0/

\section{REFERENCES}

1. Walley $\mathrm{T}$, Folino-Gallo $\mathrm{P}$, Stephens $\mathrm{P}$, et al. Trends in prescribing and utilization of statins and other lipid lowering drugs across Europe 1997-2003. Br J Clin Pharmacol 2005;60:543-51.

2. Walley $T$, Folino-Gallo $P$, Schwabe U, et al. Variations and increase in use of statins across Europe: data from administrative databases. BMJ 2004;328:385-6.

3. Ruokoniemi P, Helin-Salmivaara A, Klaukka T, et al. Shift of statin use towards the elderly in 1995-2005: a nation-wide register study in Finland. Br J Clin Pharmacol 2008;66:405-10.

4. Salomaa V, Pääkkönen $\mathrm{R}$, Hämäläinen $\mathrm{H}$, et al. Use of secondary preventive medications after the first attack of acute coronary syndrome. Eur J Cardiovasc Prev Rehabil 2007;14:386-91.

5. Vehko T, Manderbacka K, Arffman M, et al. Changing patterns of secondary preventive medication among newly diagnosed coronary heart disease patients with diabetes in Finland: a register-based study. Scand J Public Health 2010;38:317-24.

6. Suomalaisen Lääkäriseuran Duodecimin, Suomen sisätautilääkäreiden yhdistyksen ja Diabetesliiton lääkärineuvoston asettama työryhmä. Diabeteksen Käypä hoito -suositus (in Finnish: Current Care guideline: the treatment of diabetes). Duodecim 2007;123:1490-520.

7. Suomalaisen Lääkäriseuran Duodecimin ja Suomen Sisätautilääkärien Yhdistys ry:n asettama työryhmä (Working group set up by the Finnish Medical Society Duodecim and Finnish Society of Internal Medicine). Dyslipidemiat Käypä hoito-suositus (in Finnish: Current Care guideline: dyslipidaemias). Duodecim 2009;125:1011-12.

8. Wood D, de Backer G, Faergeman O, et al. Sepelvaltimotaudin ehkäisy käytännön lääkärintyössä. Yhteenveto eri yhdistysten yhteisen työryhmän (Second Joint Task Force of European and other Societies) suosituksesta (in Finnish: prevention of coronary heart disease in clinical practice. Summary of Second Joint Task Force of European and other Societies recommedations 1998.). Suom Laakaril 1999;54:2107-14.

9. Sepelvaltimotaudin ehkäisy käytännön lääkärintyössä European Society of Cardiologyn, European Atherosclerosis Societyn ja European Society of Hypertensionin Task Forcen suosituksen pohjalta laadittu suomalainen sovellus. (In Finnish: Prevention of coronary heart disease in clinical practice. Recommendations of the Task Force of the European Society of Cardiology, European Atherosclerosis Society and European Society of Hypertension in the Finnish context). Suom Laakaril 1996;51:783.

10. Ryden L, Standl E, Bartnik M, et al. Guidelines on diabetes, pre-diabetes, and cardiovascular diseases: executive summary. The task force on diabetes and cardiovascular diseases of the European Society of Cardiology (ESC) and of the European Association for the Study of Diabetes (EASD). Eur Heart J 2007;28:88-136.

11. Saaristo T, Peltonen M, Keinänen-Kiukaanniemi S, et al. National Type 2 Diabetes Prevention Programme in Finland: FIN-D2D. Int J Circumpolar Health 2007;66:101-12.

12. National Agency for Medicines, Social Insurance Institution. Finnish statistics on medicines 2000 (in Finnish: Suomen lääketilasto 2000). Helsinki: National Agency for Medicines; Social Insurance Institution, 2001.

13. Ahonen R, Martikainen J, eds. The first year of generic substitution. Helsinki:The Social Insurance Institution, Finland, Social security and health reports 2005;68:86.

14. Fhärm E, Rolandsson O, Weinehall L. Guidelines improve general trend of lowered cholesterol levels in type 2 diabetes patients in spite of low adherence. Scand J Public Health 2008;36:69-75.

15. Eliasson B, Svensson AM, Miftaraj M, et al. Clinical use and effectiveness of lipid lowering therapies in diabetes mellitus-an observational study from the Swedish National Diabetes Register. PLOS ONE 2011;6:e18744.

16. Selmer R, Sakshaug S, Skurtveit $S$, et al. Statin treatment in a cohort of 20212 men and women in Norway according to cardiovascular risk factors and level of education. $\mathrm{Br} J$ Clin Pharmacol 2009;67:355-62.

17. Colhoun HM, Dong W, Barakat MT, et al. The scope for cardiovascular disease risk factor intervention among people with diabetes mellitus in England: a population-based analysis from the Health Surveys for England 1991-94. Diabet Med 1999;16:35-40.

18. Teeling M, Bennett $\mathrm{K}$, Feely J. The influence of guidelines on the use of statins: analysis of prescribing trends 1998-2002. Br J Clin Pharmacol 2005;59:227-32.

19. Raum E, Lietzau S, Stegmaier C, et al. For the majority of patients with diabetes blood pressure and lipid management is not in line with recommendations. Results from a large population-based cohort in Germany. Pharmacoepidemiol Drug Saf 2008;17:485-94.

20. Berthold HK, Gouni-Berthold I, Bohm M, et al. Patterns and predictors of statin prescription in patients with type 2 diabetes. Cardiovasc Diabetol 2009;8:25.

21. McAlister FA, Lawson FM, Teo KK, et al. Randomised trials of secondary prevention programmes in coronary heart disease: systematic review. BMJ 2001;323:957-62.

22. Soljak MA, Majeed A, Eliahoo J, et al. Ethnic inequalities in the treatment and outcome of diabetes in three English Primary Care Trusts. Int J Equity Health 2007;6:8.

23. Avogaro A, Guida P, Giorda C, et al. The under-use of statin in type 2 diabetic patients attending diabetic clinics in Italy. Nutr Metab Cardiovasc Dis 2007;17:32-40.

24. Mantel-Teeuwisse AK, Verschuren WM, Klungel OH, et al. Recent trends in (under)treatment of hypercholesterolaemia in the Netherlands. Br J Clin Pharmacol 2004;58:310-16.

25. Toth PP, Zarotsky V, Sullivan JM, et al. Dyslipidemia treatment of patients with diabetes mellitus in a US managed care plan: a retrospective database analysis. Cardiovasc Diabetol 2009;8:26.

26. Segars LW, Lea AR. Assessing prescriptions for statins in ambulatory diabetic patients in the United States: a national, cross-sectional study. Clin Ther 2008;30:2159-66.

27. Wan $Q$, Harris MF, Jayasinghe UW, et al. Quality of diabetes care and coronary heart disease absolute risk in patients with type 2 diabetes mellitus in Australian general practice. Qual Saf Health Care 2006;15:131-5. 
28. Dominguez $\mathrm{H}$, Schramm TK, Gislason $\mathrm{GH}$, et al. National background is associated with disparities in initiation and persistence to statin treatment in subjects with diabetes in Denmark. Front Pharmacol 2010;1:142.

29. Dominguez H, Schramm TK, Norgaard ML, et al. Initiation and persistence to statin treatment in patients with diabetes receiving glucose-lowering medications 1997-2006. Open Cardiovasc Med J 2009;3:152-9.

30. Brown AF, Gross AG, Gutierrez PR, et al. Income-related differences in the use of evidence-based therapies in older persons with diabetes mellitus in for-profit managed care. J Am Geriatr Soc 2003;51:665-70.

31. National Agency for Medicines, Social Insurance Institution. Finnish statistics on medicines 2006 (Suomen lääketilasto 2006). Helsinki: Edita Prima Oy, 2007.

32. Sund R, Koski S. FinDM II-On the register-based measurement of the prevalence and incidence of diabetes and its long-term complications. A technical report. Tampere: Finnish Diabetes Association, 2009. http://www.diabetes.fi/files/1167/DehkoFinDM_ Raportti ENG.pdf (accessed May 2013).

33. Peltola $\bar{M}$, Juntunen $M$, Häkkinen $U$, et al. A methodological approach for register-based evaluation of cost and outcomes in health care. Ann Med 2011;43(Suppl 1):S4-13.

34. WHO. WHO Collaborating Centre for Drug Statistics Methodology. WHO, 2006. http://www.whocc.no/atcddd/ (accessed May 2013).
35. Liddell FDK. Simple exact analysis of the standardised mortality ratio. J Epidemiol Community Health 1984;38:85-8.

36. Forssas E, Sund R, Manderbacka K, et al. Sepelvaltimotaudin riskitekijöiden lääkehoito on tehostunut diabeetikoilla (in Finnish with abstract in English: The proportion of diabetic people using cholesterol lowering and antihypertensive medication has increased in Finland). Suom Laakaril 2011;66:3569-75.

37. Costa J, Borges M, David C, et al. Efficacy of lipid lowering drug treatment for diabetic and non-diabetic patients: meta-analysis of randomised controlled trials. BMJ 2006;332:1115-24

38. Rajpathak SN, Kumbhani DJ, Crandall J, et al. Statin therapy and risk of developing type 2 diabetes: a meta-analysis. Diabetes Care 2009;32:1924-9.

39. Doshi JA, Zhu J, Lee BY, et al. Impact of a prescription copayment increase on lipid-lowering medication adherence in veterans. Circulation 2009;119:390-7.

40. Korda RJ, Clements MS, Dixon J. Socioeconomic inequalities in the diffusion of health technology: uptake of coronary procedures as an example. Soc Sci Med 2011;72:224-9.

41. Bartlett C, Doyal L, Ebrahim S, et al. The causes and effects of socio-demographic exclusions from clinical trials. Health Technol Assess 2005;9(38):iii,iv, ix-x, 1-152.

42. Saastamoinen L. Statiini vaihdetaan harvoin edullisemmasta takaisin alkuperäiseen (in Finnish: Statins exchanges back to original is rare). Suom Laakaril 2008;63:282-4.

\begin{tabular}{|c|c|c|c|c|}
\hline \multirow[b]{2}{*}{ Comorbidity } & \multicolumn{2}{|c|}{ Hospital discharge register } & \multirow{2}{*}{$\begin{array}{l}\text { Register on medical special } \\
\text { reimbursements } \\
\text { Sll code }\end{array}$} & \multirow{2}{*}{$\begin{array}{l}\text { Register on reimbursed } \\
\text { drug purchases } \\
\text { ATC code }\end{array}$} \\
\hline & ICD-9 & ICD-10 & & \\
\hline $\begin{array}{l}\text { Alcohol-related } \\
\text { problems }\end{array}$ & $291^{\star}, 304^{\star}-305^{\star}$ & $\mathrm{F} 10^{*}-\mathrm{F} 19^{*}$ & $\mathrm{~N} / \mathrm{A}$ & $\mathrm{N} / \mathrm{A}$ \\
\hline Atherosclerosis & $440^{\star}$ & $170^{*}$ & & \\
\hline Cancer & $140^{*}-208^{*}$ & $\begin{array}{l}\mathrm{C} 00^{*}-\mathrm{C} 99^{*} \\
\mathrm{D} 00^{*}-\mathrm{D} 09^{*}\end{array}$ & $\begin{array}{l}115,116,117,128,130,180 \\
184,185,189,311,312,316\end{array}$ & L01* except L01BA01 \\
\hline COPD and asthma & $4912^{*} ; 496^{*} ; 493^{*}$ & $\mathrm{~J} 44^{\star}-\mathrm{J} 46^{*}$ & 203 & $\mathrm{R} 3^{*}$ \\
\hline Dementia & $290^{\star} ; 3310^{*}$ & $\begin{array}{l}\mathrm{F} 00^{*}-\mathrm{F}^{*} 3^{*} \\
\mathrm{G} 30^{*}\end{array}$ & 307 & N06D* \\
\hline Depression & $2960^{*} ; 2961^{*}$ & $\mathrm{~F} 32^{\star}-\mathrm{F} 34^{\star}$ & $\mathrm{N} / \mathrm{A}$ & $\mathrm{N} 6 \mathrm{~A}^{*}$ \\
\hline Epilepsy & $345^{\star}$ & G40*; G41* & $111 ; 181-183$ & N03A* \\
\hline Parkinson's disease & $332^{*}$ & G20* & 110 & $\mathrm{~N}^{2} 4 \mathrm{~B}^{*}$ \\
\hline Mental disorders & $\begin{array}{l}295^{\star}-298^{\star} \text { except } \\
2960^{\star} \text { and } 2961^{\star}\end{array}$ & $\mathrm{F} 20^{*}-\mathrm{F} 31^{*}$ & 112188 & $\begin{array}{l}\text { N05A* except N05AB01 and }^{*} \\
\text { N05AB04, and no dementia }\end{array}$ \\
\hline Stroke & $430^{*}-438^{*}$ & $\begin{array}{l}160^{*}-169^{*} \\
\mathrm{G} 45^{\star} ; \mathrm{G} 46^{*}\end{array}$ & $\mathrm{~N} / \mathrm{A}$ & $\mathrm{N} / \mathrm{A}$ \\
\hline
\end{tabular}


Appendix 2 Adjusted proportions and $95 \% \mathrm{Cl}$ for the use of lipid-lowering medication (A) before and (B) after diabetes diagnosis by CHD status at the time of diabetes diagnosis.

\begin{tabular}{|c|c|c|c|c|c|c|c|c|c|c|c|c|c|c|c|}
\hline \multirow{3}{*}{$\frac{\text { Patient group }}{\text { (A) Before }}$} & \multirow{3}{*}{ Income } & \multicolumn{2}{|c|}{2000} & \multirow{2}{*}{\multicolumn{2}{|c|}{$\frac{2001}{\text { Per cent } 95 \% \mathrm{Cl}}$}} & \multirow{2}{*}{\multicolumn{2}{|c|}{$\frac{2002}{\text { Per cent } 95 \% \mathrm{Cl}}$}} & \multirow{2}{*}{\multicolumn{2}{|c|}{$\frac{2003}{\text { Per cent } 95 \% \mathrm{Cl}}$}} & \multirow{2}{*}{\multicolumn{2}{|c|}{$\frac{2004}{\text { Per cent } 95 \% \mathrm{Cl}}$}} & \multirow{2}{*}{\multicolumn{2}{|c|}{$\frac{2005}{\text { Per cent } 95 \% \mathrm{Cl}}$}} & \multirow{2}{*}{\multicolumn{2}{|c|}{$\frac{2006}{\text { Per cent } 95 \% \mathrm{Cl}}$}} \\
\hline & & \multicolumn{2}{|c|}{ Per cent $95 \% \mathrm{Cl}$} & & & & & & & & & & & & \\
\hline & & & & & \multirow[b]{2}{*}{8} & \multirow[b]{2}{*}{ (7 to 9 ) } & \multirow[b]{2}{*}{10} & \multirow[b]{2}{*}{ (9 to 12$)$} & \multirow{2}{*}{11} & \multirow{3}{*}{$\begin{array}{l}(10 \text { to } 13) \\
(13 \text { to } 16)\end{array}$} & \multicolumn{2}{|c|}{ 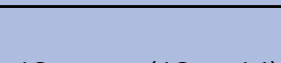 } & \multirow{3}{*}{$\begin{array}{l}14 \\
17\end{array}$} & \multirow{2}{*}{ (13 to 16$)$} \\
\hline & Lowest & 4 & (4 to 5 ) & 8 & (6 to 9 ) & & & & & & & 13 & (12 to 14$)$ & & \\
\hline & 2nd & 6 & (5 to 7 ) & 8 & (7 to 9 ) & 10 & (9 to 11$)$ & 12 & (11 to 13 ) & 14 & & 16 & (15 to 17 ) & & (16 to 19 ) \\
\hline & $3 r d$ & 6 & (6 to 7 ) & 9 & (8 to 10 ) & 11 & (9 to 12 ) & 13 & (12 to 14$)$ & 16 & (14 to 17 ) & 18 & (16 to 19 ) & 20 & (18 to 21 ) \\
\hline & 4th & 6 & (5 to 7 ) & 10 & (8 to 11 ) & 11 & (10 to 12 ) & 13 & (12 to 15 ) & 15 & (13 to 16 ) & 15 & (14 to 16 ) & 19 & (18 to 21 ) \\
\hline & Highest & 7 & (6 to 8 ) & 9 & (8 to 11$)$ & 12 & (11 to 13 ) & 12 & (11 to 14 ) & 16 & (14 to 17 ) & 18 & (17 to 20 ) & 21 & (20 to 23 ) \\
\hline \multirow{5}{*}{$\begin{array}{l}\text { Patients with } \mathrm{CHD} \\
\text { before diabetes }\end{array}$} & Lowest & 20 & (16 to 24 ) & 26 & (22 to 31$)$ & 29 & (25 to 34 ) & 32 & (28 to 38 ) & 36 & (32 to 41 ) & 36 & (32 to 42 ) & 44 & (39 to 50 ) \\
\hline & 2nd & 23 & (20 to 26 ) & 30 & (27 to 34$)$ & 35 & (31 to 38 ) & 39 & (36 to 43 ) & 43 & (39 to 46 ) & 47 & (43 to 51 ) & 49 & (45 to 53 ) \\
\hline & 3rd & 29 & (25 to 34 ) & 37 & (33 to 42 ) & 38 & (33 to 42 ) & 41 & (37 to 46 ) & 50 & (46 to 55 ) & 48 & (43 to 53 ) & 53 & (48 to 58 ) \\
\hline & 4th & 37 & (31 to 44$)$ & 34 & (28 to 40$)$ & 43 & (37 to 50$)$ & 47 & (41 to 54 ) & 50 & (45 to 57 ) & 55 & (49 to 62 ) & 60 & (53 to 67 ) \\
\hline & Highest & 35 & (28 to 43 ) & 45 & (37 to 54 ) & 49 & (41 to 57 ) & 53 & (46 to 52 ) & 60 & (53 to 69 ) & 58 & (51 to 66 ) & 67 & (59 to 76 ) \\
\hline \multirow{5}{*}{$\begin{array}{l}\text { Patients with } \\
\text { coincident CHD } \\
\text { and diabetes }\end{array}$} & Lowest & 8 & (4 to 14 ) & 5 & (3 to 10$)$ & 13 & (8 to 20 ) & 5 & (3 to 10$)$ & 10 & (6 to 16$)$ & 13 & (9 to 20 ) & 11 & (7 to 17 ) \\
\hline & 2nd & 7 & (5 to 10 ) & 10 & (7 to 13$)$ & 10 & (7 to 14$)$ & 13 & (9 to 18 ) & 10 & (7 to 14$)$ & 16 & (12 to 21 ) & 14 & (9 to 19$)$ \\
\hline & $3 r d$ & 8 & (5 to 12 ) & 9 & (6 to 15$)$ & 9 & (5 to 14$)$ & 12 & (8 to 18 ) & 15 & (10 to 20 ) & 13 & (8 to 18$)$ & 21 & (15 to 28 ) \\
\hline & 4th & 7 & (4 to 12 ) & 11 & (6 to 18 ) & 11 & (6 to 18 ) & 7 & (4 to 13 ) & 18 & (12 to 26 ) & 13 & (8 to 20 ) & 15 & (9 to 22 ) \\
\hline & Highest & 10 & (5 to 17$)$ & 10 & (5 to 17 ) & 12 & (7 to 19$)$ & 18 & (11 to 28 ) & 17 & (11 to 25 ) & 18 & (11 to 26 ) & 19 & (12 to 28 ) \\
\hline \multicolumn{16}{|l|}{ (B) After } \\
\hline \multirow{5}{*}{ Diabetes-only } & Lowest & 15 & (13 to 17 ) & 19 & (17 to 21$)$ & 23 & (21 to 25 ) & 28 & (25 to 30 ) & 33 & (30 to 35 ) & 33 & (31 to 35 ) & 35 & (33 to 37 ) \\
\hline & 2nd & 19 & (17 to 20$)$ & 20 & (18 to 21$)$ & 25 & (23 to 27 ) & 27 & (26 to 29 ) & 36 & (34 to 38 ) & 37 & (35 to 39 ) & 38 & (36 to 40 ) \\
\hline & $3 r d$ & 19 & (18 to 21 ) & 23 & (21 to 25$)$ & 25 & (23 to 27 ) & 30 & (28 to 33 ) & 37 & (35 to 40 ) & 39 & (37 to 41 ) & 40 & (38 to 43 ) \\
\hline & 4th & 21 & (20 to 24$)$ & 24 & (22 to 27$)$ & 28 & (26 to 30$)$ & 32 & (30 to 34 ) & 37 & (35 to 39 ) & 37 & (35 to 40 ) & 41 & (39 to 43 ) \\
\hline & Highest & 21 & (20 to 23 ) & 25 & (23 to 27 ) & 29 & (27 to 31 ) & 31 & (29 to 33 ) & 39 & (37 to 42 ) & 40 & (38 to 43 ) & 43 & (41 to 45 ) \\
\hline Patients with $\mathrm{CHD}$ & Lowest & 39 & (32 to 46$)$ & 42 & (36 to 49 ) & 48 & (42 to 56$)$ & 54 & (47 to 61 ) & 59 & (53 to 67 ) & 58 & (51 to 65 ) & 63 & (56 to 71 ) \\
\hline before diabetes & 2nd & 42 & (38 to 47 ) & & (44 to 54 ) & 52 & (47 to 57 ) & 57 & (52 to 63 ) & 64 & (59 to 69 ) & 64 & (59 to 70 ) & 67 & (62 to 73 ) \\
\hline & $3 r d$ & 48 & (41 to 54 ) & 55 & (48 to 62 ) & 58 & (52 to 64$)$ & 60 & (54 to 66 ) & 68 & (62 to 75$)$ & 66 & (60 to 73 ) & 69 & (63 to 76 ) \\
\hline & 4th & 58 & (50 to 67 ) & 54 & (46 to 63 ) & 59 & (51 to 67 ) & 64 & (56 to 72 ) & 67 & (59 to 75 ) & 68 & (61 to 76$)$ & 77 & (69 to 86 ) \\
\hline & Highest & 57 & (48 to 68 ) & 62 & (52 to 73 ) & 64 & (55 to 75$)$ & 64 & (55 to 75 ) & 73 & (65 to 83 ) & 74 & (65 to 83 ) & 77 & (67 to 87$)$ \\
\hline Patients with & Lowest & 59 & (47 to 74 ) & 55 & (43 to 69 ) & 60 & (47 to 74 ) & 59 & (47 to 72 ) & 64 & (52 to 79 ) & 67 & (55 to 81 ) & 65 & (53 to 79 ) \\
\hline coincident CHD & 2nd & 47 & (39 to 56$)$ & 56 & (47 to 66$)$ & 61 & (51 to 71 ) & 59 & (50 to 70 ) & 64 & (54 to 75 ) & 71 & (62 to 82$)$ & 73 & (61 to 85$)$ \\
\hline and diabetes & $3 r d$ & 51 & (40 to 63 ) & 61 & (49 to 75$)$ & 62 & (51 to 75 ) & 65 & (53 to 78 ) & 75 & (63 to 88 ) & 73 & (61 to 87 ) & 76 & (64 to 91 ) \\
\hline & 4 th & 62 & (50 to 76$)$ & 64 & (51 to 80 ) & 73 & (59 to 89 ) & 67 & (54 to 81 ) & 76 & (63 to 91 ) & 79 & (65 to 94 ) & 78 & (64 to 94 ) \\
\hline & Highest & 65 & (51 to 81 ) & 66 & (52 to 82 ) & 75 & (61 to 92$)$ & 87 & (71 to 106 ) & 76 & (62 to 93 ) & 82 & (68 to 99 ) & 76 & (61 to 94$)$ \\
\hline
\end{tabular}

CHD, coronary heart disease. 